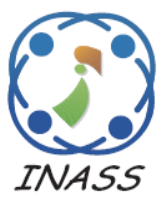

\title{
Squirrel Search Optimizer: Nature Inspired Metaheuristic Strategy for Solving Disparate Economic Dispatch Problems
}

\author{
Murugesan Suman $^{1} \quad$ Vadugapalayam Ponnuvel Sakthivel $^{2 *}$ \\ Palanigounder Duraisamy Sathya ${ }^{3}$ \\ ${ }^{1}$ Department of Electrical Engineering, Annamalai University, Chidambaram, India \\ ${ }^{2}$ Department of Electrical and Electronics Engineering, Government College of Engineering, Dharmapuri, India \\ ${ }^{3}$ Department of Electronics and Communication Engineering, Annamalai University, Chidambaram, India \\ * Corresponding author’s Email: vp.sakthivel@yahoo.com
}

\begin{abstract}
In this paper, a new meta-heuristic algorithm, called Squirrel Search Optimizer (SSO) is applied to solve various types of economic load dispatch (ELD) problems. The SSO mimics the foraging behavior of squirrels which is based on the dynamic jumping and gliding strategies. In SSO algorithm, predator presence behavior and a seasonal monitoring condition are employed to increase the search ability of the algorithm, and to balance the exploitation and exploration. The key idea of the suggested approach is to determine the optimal generation scheduling by minimizing total generation cost of units while satisfying various constraints such as power balance constraint, prohibited operating zones (POZ), ramp rate constraints and operating limits of generators. The different generating unit's characteristics, quadratic fuel cost function, non-convex fuel cost function and multiple fuel options (MFO) are also considered. The feasibility of the proposed algorithm is tested on four different power test systems having different sizes and intricacies. The results are examined in terms of both solution quality and the computational efficiency, and compared with the other approaches in the literature. The comparisons prove the robustness and effectiveness of the proposed algorithm and show that it could be used as a consistent optimizer for solving various ELD problems.
\end{abstract}

Keywords: Economic load dispatch, Meta-heuristic algorithm, Non-convex fuel cost function, Squirrel search algorithm, Valve point effect.

\section{Introduction}

\subsection{Motivation}

ELD is one of the most important concerns to be solved for a power system to operate smoothly and economically. It is a process of sharing the total load on a power system between different generating plants in order to achieve the greatest operating economy. Traditionally, the cost-power characteristics of the generating units considered in the ELD problem are approximated by a quadratic function which does not take into account the valve point loading (VPL) and the POZ. In order to increase the accuracy of the ELD modeling, the VPL effects, and POZ are considered in the costpower characteristics of the generating units. The
VPL effects and POZ will determine non-convex and non-smooth cost characteristics, and the searching space of the solutions will have multiple minimum points with discontinuities. Thus, the optimizing model of the ELD problem is non-linear with discontinuities and needs adequate solving approaches.

\subsection{Literature survey}

In the past decades, many optimization approaches including mathematical programming techniques and heuristic algorithms have been applied for solving the ELD problem. The conventional mathematical optimization techniques such as linear programming algorithms [1], dynamic programming algorithms [2], Lagrangian relaxation algorithms [3] etc. have been implemented to ELD 
issues. The classical calculus-based methods cannot perform satisfactorily to solve ELD problems due to highly non-linear features of the problem and a large number of constraints. These conventional techniques are failed to handle the ELD problem with non-smooth fuel cost function due to VPL effects.

To conquer the intricacies raised by the conventional techniques and to obtain the best possible solutions, different approaches based on artificial intelligence were developed and successfully applied to solve the ELD problem. These heuristic algorithms are used in their unique form, improved or hybridized with other algorithms. Gaing proposed Particle Swarm Optimization (PSO) to solve the ELD problem in power systems and compared with Genetic Algorithm (GA) [4]. Several nonlinear characteristics of the generator, such as ramp rate limits, POZs, and nonsmooth cost functions were considered. The GA and PSO are habitually trapped into local optima when applied to the ELD problem with VPE effects. Sakthivel [5] proposed a new PSO with Nature Inspired Dynamic Inertia Weight (PSO-NIDIW) to solve the ELD problem of power systems. In PSO-NIDIW, the inertia weight was naturally adapted on the basis of the improvement in the best fitness of the particles as the search process progresses. In [6], Firefly Algorithm (FA) was used to determine optimal solutions for the ELD problems. FA emulates the social conduct of fireflies dependent on their blazing qualities. Dubey, Pandit, and Panigrahi [7] presented Modified Flower Pollination Algorithm (MFPA) to deal the ELD problems. In the MFPA, neighborhood fertilization of FPA was constrained by a scaling component and a concentrated exploitation stage was added to determine the best solutions. Sakthivel and Sathya [8] introduced Glowworm Swarm Optimization (GSO) for solving the ELD problems with nonlinear characteristics. The GSO was a derivative-free, meta-heuristic optimization algorithm that inspired as its agents the swarm of glowworms. The agents were considered the prospective solutions to the ELD problem. A continuous version of Quick Group Search Optimizer (QGSO) algorithm was proposed to realize the ELD formulation with VPL effect, POZs, transmission losses and ramp-rate limits [9]. The searching strategy of PSO algorithm was used to update the scrounger locations. Cuckoo Search Algorithm (CSA) was developed for solving both convex and nonconvex ELD problems [10, 11]. It was inspired from the obligate brood parasitism of some cuckoo species by laying their eggs in the nests of other host birds of different species. In [12], the ELD problems were solved by using Krill Herd Algorithm (KHA). Furthermore, the performance of the KHA approach was enhanced by crossover and mutation operations of Differential Evolution (DE). Different variants of the KHA were applied to small, medium and large scale power systems. Ghorbani, and Babaei [13] implemented Exchange Market Algorithm (EMA) to solve the ELD problems with practical constraints. The EMA approach was inspired by the stock exchange trading technique. This algorithm used two searcher and two absorbent operators for individuals to be absorbed to the elite person, which resulted to creation and organization of random numbers. Backtracking Search Algorithm (BSA) [14] was introduced to deal the ELD problems with VPL impacts and MFOs. The BSA used crossover and mutation operators to explore the search domain. These operators are completely different from the GA and evolutionary programming. A new physics inspired approach, Franklin's and Coulomb's laws inspired algorithm (CFA) [15] was also developed to determine the global solutions of optimal ELD problems in power system. CFA was based on the impact of electrically charged particles on each other due to electrical attraction and repulsion forces.

\subsection{Contributions}

Recently, a new meta-heuristic algorithm, named Squirrel search optimizer (SSO) algorithm was proposed by Jain, Singh, and Rani [16]. The SSO algorithm models the foraging activities of squirrel individuals. Each squirrel individuals modifies its position using four processes namely, (1) distributing the population, (2) dynamic foraging behavior, (3) seasonal adapting intelligence and (4) random repositioning of individuals at the end of winter season. The unique features of the SSO algorithm are as follows:

- The gliding constant is used in the location update of squirrels which provides suitable steadiness between exploration and exploitation.

- The predator presence behavior is employed to abruptly change the location of squirrel which enhances the exploration ability of algorithm.

- A seasonal monitoring condition is used to prevent the suggested algorithm from being trapped in local optimal solutions.

- Levy distribution is used to find new solutions far away from the current best solution which improves the global exploration ability of the algorithm.

These features make SSO algorithm able to overcome the normal drawbacks of other algorithms 
such as premature convergence, inadequate ability to discover to find nearby extreme points and absence of efficient constraints handling mechanism. The advantages of SSO algorithm are less execution time, ability to solve different complex optimization problems and high capacity in obtaining global optimum solutions.

To the best of authors' knowledge, application of the SSO approach for ELD problems in power system has not yet been reported. In this paper, SSO is developed for solving various types of ELD problems in which different types of constraints along with the VPL effects and MFO. The effectiveness of SSO approach is validated by employing extensive test cases and comparing the results with those obtained by other techniques reported in the literature.

\subsection{Paper structure}

The remainder of the paper is organized as follows: Section 2 presents the ELD problem formulation. Sections 3 and 4 describe the SSO approach and implementation of the suggested approach to the ELD problem respectively. The description of the test system, existing heuristic approaches used for comparison, experimental results and comprehensive analysis are elaborated in Section 5, and the concluding remarks are given in Section 6.

\section{ELD problem formulation}

The goal of the ELD problem is to find an optimal power generation schedule while minimizing fuel costs and also satisfying the operating constraints of different power systems.

\subsection{Objective function}

The problem with ELD is formulated as follows:

$$
\text { Minimize } F=\sum_{i=1}^{n g} F_{i}\left(P_{i}\right)
$$

The generator's quadratic fuel cost function is defined by:

$$
F_{i}\left(P_{i}\right)=a_{i}+b_{i} P_{i}+c_{i} P_{i}^{2}
$$

The sequential valve opening in multi-valve steam turbines generates rippling effect on the fuel cost curve of the generator. To model an accurate and practical ELD solution, this VPL effects should be included in the fuel cost function as shown in

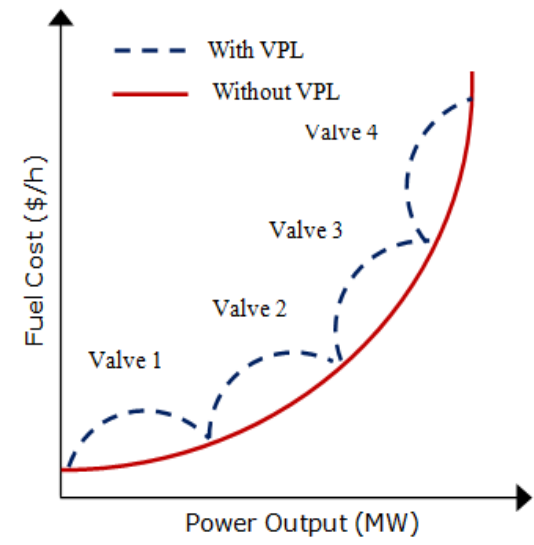

Figure. 1 Fuel cost curve with VPL impacts

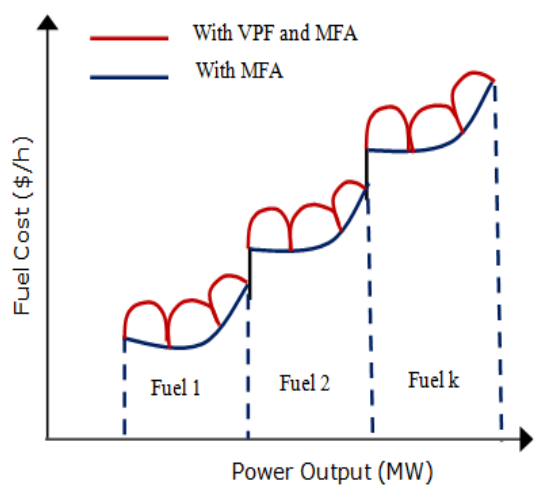

Figure. 2 Fuel cost curve with VPL and MFO impacts

Fig. 1. Then the fuel cost function of each generating unit is expressed in the non-convex form as follows.

$$
\begin{aligned}
F_{i}\left(P_{i}\right)= & a_{i}+b_{i} P_{i}+c_{i} P_{i}^{2}+ \\
& \left|d_{i} \times \sin \left(e_{i} \times\left(P_{i, \text { min }}-P_{i}\right)\right)\right|
\end{aligned}
$$

Furthermore, there are few generating units supplied with multiple fuels. In those cases, the fuel cost function of each unit is represented by a piecewise function. To model an accurate and practical ELD solution, VPL effects and MFO should be comprised in the cost function which is formulated as follows:

$$
\begin{aligned}
& F_{i}\left(P_{i}\right)=a_{i j}+b_{i j} P_{i}+c_{i j} P_{i}^{2}+ \\
& \left|d_{i j} \times \sin \left(e_{i j} \times\left(P_{i, \min }-P_{i}\right)\right)\right|
\end{aligned}
$$

if $P_{i j, \min } \leq P_{i} \leq P_{i j, \max }, \mathrm{j}=1, \ldots, \mathrm{nf}$

The fuel cost function with VPL impacts and MFO are depicted in Fig. 2. 


\subsection{System constraints}

\subsubsection{Power balance constraints}

The generators' complete power output must be equal to the sum of power requirements and complete transmission losses and is provided by:

$$
\sum_{i=1}^{n g} P_{i}=P_{D}+P_{L}
$$

The transmission losses are expressed as

$$
P_{L}=\sum_{i=1}^{n g} \sum_{j=1}^{n g} P_{i} B_{i j} P_{j}+\sum_{i=1}^{n g} B_{0 i} P_{i}+B_{00}(6)
$$

\subsubsection{Generator capacity constraints}

Each unit's output power needs to be restricted by limiting inequality between its limits. This constraint is represented by

$$
P_{i, \min } \leq P_{i} \leq P_{i, \max }
$$

\subsubsection{Ramp rate constraints}

The operating range of all generating units is practically restricted by their ramp rate limits to operate continually between two closest specific operating zones. The power output of all generating units is controlled by the ramp rate constraint and is provided as follows:

$$
\begin{aligned}
& P_{i}-P_{i}^{0} \leq U R_{i} \\
& P_{i}^{0}-P_{i} \leq D R_{i}
\end{aligned}
$$

\subsubsection{Prohibited operating zone}

The POZs are due to steam valve operation or vibrations in the shaft bearings. The viable operating zones of unit $\mathrm{j}$ can be defined as follows:

$$
\begin{aligned}
& P_{i, \text { min }} \leq P_{i} \leq P_{i, 1}^{L} \\
& P_{i, k-1}^{U} \leq P_{i} \leq P_{i, k}^{L} \quad k=2, \ldots \ldots n z \\
& P_{i, n z}^{U} \leq P_{i} \leq P_{i, \text { max }}
\end{aligned}
$$

\section{Squirrel search optimizer}

The hunt procedure starts when flying squirrels begin scavenging [16]. During fall, the squirrels look for nourishment assets by skimming from one tree to the next. At the same time, they change their area and investigate various regions of woods. As the climatic conditions are sufficiently hot, they can meet their every day vitality needs more rapidly on the eating routine of oak seeds accessible in bounty and thus they devour oak seeds quickly after discovering them. Subsequent to satisfying their day by day vitality prerequisite, they begin scanning for ideal nourishment hotspot for winter (hickory nuts). Capacity of hickory nuts will help them in keeping up their vitality prerequisites in amazingly brutal climate and decrease the expensive searching excursions and in this way increment the likelihood of endurance.

During winter, lost leaf spread in deciduous woodlands results an expanded danger of predation and thus they become less dynamic yet don't sleep in winter. Toward the finish of winter season, flying squirrels again become dynamic. This is a monotonous procedure and proceeds till the life expectancy of a flying squirrel and structures the establishment of SSO.

The SSO refreshes the places of squirrels as indicated by the ebb and flow season, the sort of squirrels and if chasers show up.

\subsection{Instate the population}

Expecting that the quantity of the populace is $\mathrm{N}$, the upper and lower limits of the pursuit space are $X_{U}$ and $X_{L} . N$ squirrels are arbitrarily created as follows:

$$
X_{i}=X_{L}+\operatorname{rand}(1, D) \times\left(X_{U}-X_{L}\right)
$$

where, $X_{i}$ indicates the $i$ th squirrel, $(i=1: N)$; rand is an random number somewhere in the range of 0 and $1 ; D$ is the measurement of the issue.

\subsection{Group the population}

SSO requires that there is just a single squirrel at each tree, accepting the absolute number of the squirrels is $N$, subsequently, there are $N$ trees in the woods. All the $N$ trees contain one hickory tree and $N_{a}$ oak seed trees; the others are typical trees that have no nourishment. The hickory tree is the best nourishment asset for the squirrels and the oak seed tree comes in just short of the win. Positioning the fitness estimations of the populace in rising request, the squirrels are separated into three kinds:

- $\quad$ squirrels situated at hickory trees $\left(W_{h}\right)$,

- $\quad$ squirrels situated at oak seed trees $\left(W_{a}\right)$ and

- $\quad$ squirrels situated at ordinary trees $\left(W_{n}\right)$.

\subsection{Refresh the location of squirrels}

The squirrels refresh their situations by skimming to the hickory trees or oak seed trees as follows:

$$
X_{i}^{t+1}= \begin{cases}X_{i}^{t}+d_{g} G_{c}\left(X_{a i}^{t}-X_{i}^{t}\right) & \text { if } r_{1} \geq P_{d p} \\ \text { Random location } & \text { otherwise }\end{cases}
$$




$$
X_{i}^{t+1}=\left\{\begin{array}{cc}
X_{i}^{t}+d_{g} G_{c}\left(X_{h}^{t}-X_{i}^{t}\right) & \text { if } r_{2} \geq P_{d p} \\
\text { Random location } & \text { otherwise }
\end{array}\right.
$$

$P_{d p}$ is esteemed at 0.1 indicates the chaser likelihood. In the event that $r>P_{d p}$, at that point no chaser shows up, the squirrels coast in the backwoods to discover the nourishment, and the squirrels are protected; if $r<P_{d p}$, the chasers show up, the squirrels are compelled to limit the extent of exercises, the squirrels are imperilled, and their locations are migrated arbitrarily. $d_{g}$ is the skimming separation that can be determined by

$$
d_{g}=\frac{h_{g}}{\tan \varnothing}
$$

where, $h_{g}$ is the consistent esteemed $8 ; \tan (\phi)$ indicates the coasting point that can be determined by

$$
\tan \varnothing=\frac{D}{L}
$$

The drag power and lift power can be estimated as follows:

$$
\begin{aligned}
& D=\frac{1}{2 \rho V^{2} S C_{D}} \\
& L=\frac{1}{2 \rho V^{2} S C_{L}}
\end{aligned}
$$

\subsection{Occasional changeover verdict and arbitrary refreshing}

Toward the start of every generation, the SSO necessitates that the entire populace is in winter, which implies all the squirrels are refreshed by Eqs. (11) and (12) At the point the squirrels are refreshed, regardless of whether the season change is decided by the following formulae.

$$
\begin{gathered}
S_{c}^{t}=\sqrt{\sum_{k=1}^{d}\left(X_{a i, k}^{t}-X_{h, k}^{t}\right)^{2}} \quad i=1,2, \ldots, N_{a} \\
S_{\min }=\frac{10 e^{-6}}{(365)^{t /\left(t_{\max } / 2.5\right)}}
\end{gathered}
$$

If $S_{t c}<S_{\min }$, winter is finished and the season goes to summer, something else, the season is unaltered. At the point when the season goes to summer, all the people who float to $W_{h}$ remain at the refreshed area, and all the squirrels who skim to $W_{a}$ and don't meet with chasers move their situations as follows:

$$
X_{\text {inew }}^{t+1}=X_{L}+L e^{\prime} v y(x) \times\left(X_{U}-X_{L}\right)
$$

$$
L e^{\prime} v y(x)=0.01 \times \frac{\alpha \times r_{a}}{\left|r_{b}\right|^{\frac{1}{\beta}}}
$$

Le'vy is the arbitrary walk model whose progression complies with the Le'vy appropriation and can be determined by

$$
L e^{\prime} v y(x)=0.01 \times \frac{\alpha \times r_{a}}{\left|r_{b}\right|^{\frac{1}{\beta}}}
$$

$\alpha$ is determined as

$$
\alpha=\left[\frac{\Gamma(1+\beta) \times \sin \left(\frac{\pi \beta}{2}\right)}{\Gamma\left(\frac{1+\beta}{2}\right) \times \beta \times 2\left(\frac{\beta-1}{2}\right)}\right]^{\frac{1}{\beta}}
$$

\section{Implementation of SSO to ELD problems}

In this article, the proposed SSO algorithm is developed and effectively implemented for solving different types of ELD problems. The different steps of SSO algorithm for solving ELD problems are described below.

Step 1: Generate the generation values randomly within the specified limits for every generating unit in each solution or squirrel as follows

$$
\left[\begin{array}{c}
P^{1} \\
P^{2} \\
\vdots \\
P^{n}
\end{array}\right]=\left[\begin{array}{cccc}
P_{1,1} & P_{1,2} & \cdots & P_{1, n g} \\
P_{2,2} & P_{2,2} & \cdots & P_{2, n g} \\
\vdots & \vdots & \cdots & \vdots \\
P_{n, 1} & P_{n, 2} & \cdots & P_{n, n g}
\end{array}\right]
$$

Step 2: Apply the renovate strategy to satisfy the power balance constraint and modify the generation value for POZ constraint violation.

Step 3: Evaluate the objective values of all the squirrels using Eq. (3).

Step 4: Sort the fitness values of each squirrel's location in ascending order.

Step 5: Declare the flying squirrel with minimal fitness value is on the hickory nut tree (optimal food source), the next three best flying squirrels are on the acorn tree (normal food source) and the remaining squirrels are on the normal trees (no food source).

Step 6: Update the position of squirrels which are on the acorn and normal trees as described in Section 3.3. 
Step 7: Randomly relocate the positions of some squirrels when seasonal monitoring condition is satisfied.

Step 8: If the maximum number iterations are reached, output the location of squirrel on hickory nut tree as the optimal solution for the ELD problem. Otherwise go to Step 2.

\section{Simulation results}

To evaluate the effectiveness of the newly developed meta-heuristic algorithm, SSO, the ELD problems with smooth and non-smooth quadratic cost functions, transmission losses, ramp rate limits, VPL effects and MFO are solved, and four different power test systems with different sizes and intricacies are considered. The ELD problems are implemented in Matlab 7.1 and executed on an Intel core i3 processor with 4GB RAM personal computer. The results obtained using SSO algorithm are compared with results of other methods reported in literature. In order to compare the performance of the SSO, the 50 independent runs are made and the results of the minimum, maximum and mean fuel costs and standard deviation are tabulated for each test system. The parameter settings of the proposed SSO are as follows:

- Number of hickory tree $=1$

- Number of acorny trees, $\mathrm{N}_{\mathrm{a}}=3$

- Number of trees (Population size) $=20$

- $\quad$ Maximum number of generations, $\mathrm{t}_{\max }=100$

- $\quad$ Gliding constant, $G c=1.9$

- Density of air, $\rho=1.204 \mathrm{kgm}^{-3}$

- $\quad$ Speed, $V=5.25 \mathrm{~ms}^{-1}$

- $\quad$ surface area of body $S=154 \mathrm{~cm}^{2}$

- $\quad$ Drag coefficient $C_{D}=0.6$

- $\quad$ Lift coefficients $C_{L}=0.675 \leq C_{L} \leq 1.5$

\subsection{Description of the test systems}

The SSO is applied on four different power systems: (1) System with 6-unit system with POZs, ramp rate limits and transmission losses; (2) 10-unit system with VPL and MFOs; (3) 40-unit system with VPL impacts; (4) 140-units system with VPL impacts.

\subsection{Brief overview of compared heuristic approaches}

Results of the SSO algorithm are compared with the following heuristic approaches.

BSA [14]: The BSA utilizes three essential genetic operators: selection, mutation and crossover to create new individuals. It has a random mutation method which utilizes one direction individual for each target individual, in contrast with the GA and DE approaches.

CFA [15]: The CFA algorithm is derived from the Coulomb's and Franklin's theories, and comprises attraction/repulsion, probabilistic ionization, and contact phases.

CSA [10, 11]: CSA is inspired from the obligate brood parasitism of some cuckoo species by laying their eggs in the nests of other host birds of other species. It is glorified such breeding conduct in combination with Lévy flights behavior of some birds and fruit flies for applying to different optimization problems.

EMA [13]: This algorithm is inspired by the financial exchange wherein the investors purchase and sell any kinds of shares under various economic situations. In contrast to different algorithms, this algorithm has two searcher and two absorbent operators which empower the algorithm to search around the optimum solution.

FA [6]: FA is inspired by the glimmering behavior of fireflies in the summer sky in the tropical temperature regions. It depends on the following glorified conduct of the flashing characteristics of fireflies: all fireflies are unisex; the level of attractiveness of a firefly is proportional to its brightness; and the brightness of a firefly is evaluated by objective function value of a given problem.

FPA [7]: FPA is mimicked by pollination procedure of blooming plants in nature. It adopts the conduct of blossoming plants for the solution of constrained optimization problems.

GSO [9]: GSO is inspired by animal searching behavior which depends on the producer-scrounger model. Animal scanning methods are utilized figuratively to model optimum searching strategies to solve continuous optimization problems.

KHA [12]: KHA is based on the herding behavior of krill individuals. Each krill individuals modify its position using three processes as follows: movement induced by other individuals; foraging motion; and random physical diffusion. It is also combined with opposition based learning to improve the convergence speed of the basic KHA algorithm [17].

PSO-NIDIW [5]: PSO is inspired by the social behavior of bird flocking and fish schooling, whereas NIDIW is mimicked by the social behavior of humans which is proposed to cogently balance the global exploration and local exploitation abilities for PSO. The performance of the PSO-NIDIW algorithm is improved by this fine strategy of naturally adjusting dynamic inertia weight. 


\subsection{Performance comparison}

\subsubsection{Test system 1}

In this test system, a standard six generating units with a power demand of $1263 \mathrm{MW}$ is considered. This test system ponders the transmission loss, ramp rate limits and POZ effects. The system data, loss formula coefficients and cost coefficients are given in Ref. [4]. The optimal generation schedule, fuel cost and transmission loss obtained by the SSO are depicted in Table 1. It is evident from Table 1 that the proposed SSO approach minimizes the fuel cost function without violating the system constraints such as ramp rate and POZ limits. The minimum, mean and maximum fuel costs and standard deviation obtained by SSO algorithm are compared with the other approaches in Table 2. It is seen that the minimum, mean and maximum fuel costs obtained by the SSO algorithm are very close to each other which proves the robustness of the proposed approach. Furthermore, SSO algorithm provides lesser standard deviation than the compared original, improved and hybrid algorithms which confirms the stability of the proposed approach.

\subsubsection{Test system 2}

The SSO algorithm is applied to solve the ELD problem for a 10 units system with VPL effects and

Table 1. Optimal generations schedule of various algorithms for test system 1

\begin{tabular}{|c|c|}
\hline Unit (MW) & SSO \\
\hline $\mathrm{P}_{1}$ & 447.0936 \\
\hline $\mathrm{P}_{2}$ & 172.9299 \\
\hline $\mathrm{P}_{3}$ & 263.9487 \\
\hline $\mathrm{P}_{4}$ & 138.6932 \\
\hline $\mathrm{P}_{5}$ & 164.9655 \\
\hline $\mathrm{P}_{6}$ & 87.7593 \\
\hline $\mathrm{P}_{\mathrm{L}}$ & 12.3902 \\
\hline Minimum cost $(\$ / \mathrm{h})$ & 15442.4 \\
\hline
\end{tabular}

Table 2. Comparison and statistical analysis of various algorithms for test system 1

\begin{tabular}{|c|c|c|c|}
\hline Approach & $\begin{array}{c}\text { Min. cost } \\
\mathbf{( \$ / h )}\end{array}$ & $\begin{array}{c}\text { Mean cost } \\
\mathbf{( \$ / h )}\end{array}$ & $\begin{array}{c}\text { Standard } \\
\text { deviation }\end{array}$ \\
\hline BSA [14] & 15449.8995 & 15449.9001 & - \\
\hline $\begin{array}{c}\text { PSO- } \\
\text { NIDIW [5] }\end{array}$ & 15449 & 15449 & - \\
\hline GSO [9] & 15,448 & 15450 & \\
\hline CSA [11] & 15443.08 & - & - \\
\hline KHA [12] & 15443.0752 & 15443.1863 & - \\
\hline EMA [13] & 15443.075 & 15443.075 & - \\
\hline CFA [15] & 15442.6553 & 15442.6735 & 0.0119 \\
\hline SSO & 15442.4 & 15442.6 & 0.0352 \\
\hline
\end{tabular}

Table 3. Optimal generations schedule of various algorithms for test system 2

\begin{tabular}{|c|c|c|}
\hline Unit (MW) & $\begin{array}{c}\text { Fuel } \\
\text { Types }\end{array}$ & SSO \\
\hline $\mathrm{P}_{1}$ & 2 & 218.5032 \\
\hline $\mathrm{P}_{2}$ & 1 & 212.3104 \\
\hline $\mathrm{P}_{3}$ & 1 & 280.4736 \\
\hline $\mathrm{P}_{4}$ & 3 & 239.5643 \\
\hline $\mathrm{P}_{5}$ & 1 & 278.5875 \\
\hline $\mathrm{P}_{6}$ & 3 & 239.7953 \\
\hline $\mathrm{P}_{7}$ & 1 & 288.0741 \\
\hline $\mathrm{P}_{8}$ & 3 & 239.8211 \\
\hline $\mathrm{P}_{9}$ & 3 & 426.4850 \\
\hline $\mathrm{P}_{10}$ & 1 & 276.0857 \\
\hline $\begin{array}{l}\text { Minimum } \\
\text { cost }(\$ / \mathrm{h})\end{array}$ & \multicolumn{2}{|c}{623.7129} \\
\hline \multicolumn{2}{|c}{} \\
\hline
\end{tabular}

Table 4. Comparison and statistical analysis of various algorithms for test system 2

\begin{tabular}{|c|c|c|c|}
\hline Approach & $\begin{array}{c}\text { Min. cost } \\
\mathbf{( \$ / h )}\end{array}$ & $\begin{array}{c}\text { Mean cost } \\
\mathbf{( \$ / h )}\end{array}$ & $\begin{array}{c}\text { Standard } \\
\text { deviation }\end{array}$ \\
\hline CFA [15] & 623.9576 & 623.9702 & 0.0105 \\
\hline BSA [14] & 623.9016 & 623.9757 & - \\
\hline CSA [10] & 623.8684 & 623.9495 & 0.2438 \\
\hline SSO & 623.7129 & 624.2592 & 0.126 \\
\hline
\end{tabular}

MFO in which the transmission line losses are neglected. The power demand of this system is chosen as $2700 \mathrm{MW}$.

The system data and concerned constraints values of this test system are taken from Ref. [5]. Table 3 confers the best power dispatch schedule with optimum fuel types and settings using various heuristic approaches. The fuel cost obtained by SSO approach is $623.7129 \$ / \mathrm{h}$ with no constraints violation that indicates high accuracy of the proposed approach. The statistical results of minimum, mean and maximum fuel costs, standard deviation and CPU time are summarized in Table 4, which show that the SSO approach obtains better quality solutions than the compared algorithms and has a good stability in the 50 independent runs. Furthermore, it is noticed that the proposed SSO is faster than the other optimization approaches available in the literature.

\subsubsection{Test system 3}

This system consists of 40 units with VPL effects. The system data is adopted from Ref. [14]. The power demand is $10,500 \mathrm{MW}$. Table 5 compares obtained results by the proposed SSO algorithm with the other state of the art optimization 
Table 5. Optimal generations schedule of SSO algorithm for test system 3

\begin{tabular}{|c|c|c|c|}
\hline Unit & $\begin{array}{c}\text { Output } \\
\text { power (MW) }\end{array}$ & Unit & $\begin{array}{c}\text { Output } \\
\text { power }(\mathbf{M W})\end{array}$ \\
\hline $\mathrm{P}_{1}$ & 110.8020 & $\mathrm{P}_{21}$ & 523.27668 \\
\hline $\mathrm{P}_{2}$ & 110.8020 & $\mathrm{P}_{22}$ & 523.27658 \\
\hline $\mathrm{P}_{3}$ & 97.3983 & $\mathrm{P}_{23}$ & 523.27789 \\
\hline $\mathrm{P}_{4}$ & 179.7113 & $\mathrm{P}_{24}$ & 523.27688 \\
\hline $\mathrm{P}_{5}$ & 87.8014 & $\mathrm{P}_{25}$ & 523.2768 \\
\hline $\mathrm{P}_{6}$ & 140 & $\mathrm{P}_{26}$ & 523.2768 \\
\hline $\mathrm{P}_{7}$ & 259.5986 & $\mathrm{P}_{27}$ & 10.00 \\
\hline $\mathrm{P}_{8}$ & 284.5886 & $\mathrm{P}_{28}$ & 10.00 \\
\hline $\mathrm{P}_{9}$ & 284.5886 & $\mathrm{P}_{29}$ & 10.00 \\
\hline $\mathrm{P}_{10}$ & 130.00 & $\mathrm{P}_{30}$ & 87.7979 \\
\hline $\mathrm{P}_{11}$ & 94 & $\mathrm{P}_{31}$ & 190 \\
\hline $\mathrm{P}_{12}$ & 94 & $\mathrm{P}_{32}$ & 190 \\
\hline $\mathrm{P}_{13}$ & 214.7583 & $\mathrm{P}_{33}$ & 190 \\
\hline $\mathrm{P}_{14}$ & 394.2798 & $\mathrm{P}_{34}$ & 164.7987 \\
\hline $\mathrm{P}_{15}$ & 394.2798 & $\mathrm{P}_{35}$ & 194.3694 \\
\hline $\mathrm{P}_{16}$ & 394.2798 & $\mathrm{P}_{36}$ & 200 \\
\hline $\mathrm{P}_{17}$ & 489.2813 & $\mathrm{P}_{37}$ & 110 \\
\hline $\mathrm{P}_{18}$ & 489.2813 & $\mathrm{P}_{38}$ & 110 \\
\hline $\mathrm{P}_{19}$ & 511.2789 & $\mathrm{P}_{39}$ & 110 \\
\hline $\mathrm{P}_{20}$ & 511.2789 & $\mathrm{P}_{40}$ & 511.2769 \\
\hline Minimum & & 121412.3477 \\
\hline $\operatorname{cost}(\$ / \mathrm{h})$ & & \multicolumn{2}{|l}{} \\
\hline & &
\end{tabular}

Table 6. Comparison and statistical analysis of various algorithms for test system 3

\begin{tabular}{|c|c|c|c|}
\hline Approach & $\begin{array}{c}\text { Min. cost } \\
\mathbf{( \$ / h )}\end{array}$ & $\begin{array}{c}\text { Mean cost } \\
\mathbf{( \$ / h )}\end{array}$ & $\begin{array}{c}\text { Standard } \\
\text { deviation }\end{array}$ \\
\hline FA [6] & 121415.05 & 121416.57 & 1.784 \\
\hline FPA [7] & 121414.6184 & 121441.2461 & - \\
\hline KHA [12] & 121412.5991 & 121413.1454 & - \\
\hline EMA [13] & 121412.5355 & 121417.1328 & - \\
\hline SSO & 121412.3477 & 121412.9743 & 0.5864 \\
\hline
\end{tabular}

techniques. From Table 5, it is seen that the minimum fuel cost obtained by the SSO algorithm is lower than the other approaches. The minimum fuel cost obtained by SSO algorithm is 121412.347706 $\$ / \mathrm{hr}$. Table 6 imparts the comparison of the statistical results of the SSO and other heuristic algorithms. In this case, the SSO algorithm outperforms all the other algorithms in terms of obtaining better solution quality with less computational effort.

\subsubsection{Test system 4}

This system, namely Korean power system is a large scale test case which consists of 140 generating units. This test system is fossil fuel based power system in which 40 thermal units, 51 gas units, 20 nuclear units and 29 oil units are incorporated.

The VPL effects are considered in 6 thermal units, 4 gas units and 2 oil units. The POZs are deliberated in 4 generating units. The input data are taken from Ref. [19]. The total demand is 49,342 MW. The optimal dispatch solution with proposed SSO algorithm is conferred in Table 7. The minimum, mean and maximum fuel costs, standard deviation and CPU time among 50 runs of solutions obtained from proposed SSO, GSO [9], CQGSO [9], CSA [11], KHA [17] and OKHA [17] are compared in Table 8. It is noticeable from Table 8 that the fuel cost acquired by using SSO is the lowest among all other approaches.

\subsubsection{Convergence and computational efficiency}

Fig. 3 shows the convergence characteristics of SSO algorithm for test system 4 . It can be seen that the SSO is congregate to the optimal solutions in earlier iterations even in large scale power system (test system 4) and confirms the fast convergence speed of the proposed approach. The average CPU times of SSO approach for different power systems are shown in Fig. 4. It is observed from Tables 2, 4, 6 and 8, the fuel costs achieved by the SSO algorithm are lesser than the reported approaches in the literature. Also, the SSO approach is also computationally efficient.

\subsubsection{Robustness}

From Tables 2, 4, 6 and 8, it is perceptible that the minimum fuel cost obtained by SSO approach is least compared with other heuristic techniques highlighting its better solution quality. The dissemination of the fuel cost obtained by SSO algorithm for test system 4 in 50 independent runs are shown in Fig. 3. From Fig. 5, the minimum fuel cost obtained by SSO algorithm in 50 independent runs for test system 4 is in the range of 1559.818 to $1559.875 \mathrm{k} \$ / \mathrm{hr}$. The occurrence of attaining the fuel costs within the mean cost is also the highest. Thus the SSO algorithm is robust and more stable in accomplishing the feasible solutions.

This is due to the realistic modelling of determination capacity of squirrels for optimal food sources. The squirrels search around the region of recently updated solutions which gives sufficient exploitation. Additionally, the unification of characteristics such as predator presence probability and seasonal monitoring conditions provide proper balance between the exploration and exploitation in the search domain. 
Table 7. Optimal generations schedule of SSO algorithm for test system 4

\begin{tabular}{|c|c|c|c|c|c|c|c|c|c|}
\hline Unit & $\begin{array}{c}\text { Output } \\
\text { power (MW) }\end{array}$ & Unit & $\begin{array}{c}\text { Output } \\
\text { power } \\
\text { (MW) }\end{array}$ & Unit & $\begin{array}{l}\text { Output } \\
\text { power } \\
\text { (MW) }\end{array}$ & Unit & $\begin{array}{l}\text { Output } \\
\text { power } \\
(\mathrm{MW})\end{array}$ & Unit & $\begin{array}{c}\text { Output } \\
\text { power } \\
(\mathrm{MW}) \\
\end{array}$ \\
\hline $\mathrm{P}_{1}$ & 116.5799 & $\mathrm{P}_{29}$ & 501 & $\mathrm{P}_{57}$ & 103 & $\mathrm{P}_{85}$ & 115 & $\mathrm{P}_{113}$ & 94 \\
\hline $\mathrm{P}_{2}$ & 189 & $\mathrm{P}_{30}$ & 501 & $\mathrm{P}_{58}$ & 198 & $\mathrm{P}_{86}$ & 207 & $\mathrm{P}_{114}$ & 94 \\
\hline $\mathrm{P}_{3}$ & 190 & $\mathrm{P}_{31}$ & 506 & $\mathrm{P}_{59}$ & 312 & $\mathrm{P}_{87}$ & 207 & $\mathrm{P}_{115}$ & 244 \\
\hline $\mathrm{P}_{4}$ & 190 & $\mathrm{P}_{32}$ & 506 & $\mathrm{P}_{60}$ & 281.1698 & $\mathrm{P}_{88}$ & 175 & $\mathrm{P}_{116}$ & 244 \\
\hline $\mathrm{P}_{5}$ & 168.6899 & $\mathrm{P}_{33}$ & 506 & $\mathrm{P}_{61}$ & 163 & $\mathrm{P}_{89}$ & 175 & $\mathrm{P}_{117}$ & 244 \\
\hline $\mathrm{P}_{6}$ & 190 & $\mathrm{P}_{34}$ & 506 & $\mathrm{P}_{62}$ & 95 & $\mathrm{P}_{90}$ & 175 & $\mathrm{P}_{118}$ & 95 \\
\hline $\mathrm{P}_{7}$ & 490 & $\mathrm{P}_{35}$ & 500 & $\mathrm{P}_{63}$ & 160 & $\mathrm{P}_{91}$ & 175 & $\mathrm{P}_{119}$ & 95 \\
\hline $\mathrm{P}_{8}$ & 490 & $\mathrm{P}_{36}$ & 500 & $\mathrm{P}_{64}$ & 160 & $\mathrm{P}_{92}$ & 580 & $\mathrm{P}_{120}$ & 116 \\
\hline $\mathrm{P}_{9}$ & 496 & $\mathrm{P}_{37}$ & 241 & $\mathrm{P}_{65}$ & 490 & $\mathrm{P}_{93}$ & 645 & $\mathrm{P}_{121}$ & 175 \\
\hline $\mathrm{P}_{10}$ & 496 & $\mathrm{P}_{38}$ & 241 & $\mathrm{P}_{66}$ & 196 & $\mathrm{P}_{94}$ & 984 & $\mathrm{P}_{122}$ & 2 \\
\hline $\mathrm{P}_{11}$ & 496 & $\mathrm{P}_{39}$ & 774 & $\mathrm{P}_{67}$ & 490 & $\mathrm{P}_{95}$ & 978 & $\mathrm{P}_{123}$ & 4 \\
\hline $\mathrm{P}_{12}$ & 496 & $\mathrm{P}_{40}$ & 769 & $\mathrm{P}_{68}$ & 488.6475 & $\mathrm{P}_{96}$ & 682 & $\mathrm{P}_{124}$ & 15 \\
\hline$P_{13}$ & 506 & $\mathrm{P}_{41}$ & 3 & $\mathrm{P}_{69}$ & 130 & $\mathrm{P}_{97}$ & 720 & $\mathrm{P}_{125}$ & 9 \\
\hline $\mathrm{P}_{14}$ & 509 & $\mathrm{P}_{42}$ & 3 & $\mathrm{P}_{70}$ & 233.8972 & $\mathrm{P}_{98}$ & 718 & $\mathrm{P}_{126}$ & 12 \\
\hline $\mathrm{P}_{15}$ & 506 & $\mathrm{P}_{43}$ & 248.8932 & $\mathrm{P}_{71}$ & 137 & $\mathrm{P}_{99}$ & 720 & $\mathrm{P}_{127}$ & 10 \\
\hline $\mathrm{P}_{16}$ & 505 & $\mathrm{P}_{44}$ & 247.3674 & $\mathrm{P}_{72}$ & 326.0975 & $\mathrm{P}_{100}$ & 964 & $\mathrm{P}_{128}$ & 112 \\
\hline $\mathrm{P}_{17}$ & 506 & $\mathrm{P}_{45}$ & 250 & $\mathrm{P}_{73}$ & 195 & $\mathrm{P}_{101}$ & 958 & $\mathrm{P}_{129}$ & 4 \\
\hline $\mathrm{P}_{18}$ & 506 & $\mathrm{P}_{46}$ & 250 & $\mathrm{P}_{74}$ & 175 & $\mathrm{P}_{102}$ & 1007 & $\mathrm{P}_{130}$ & 5 \\
\hline $\mathrm{P}_{19}$ & 505 & $\mathrm{P}_{47}$ & 240.6137 & $\mathrm{P}_{75}$ & 175 & $\mathrm{P}_{103}$ & 1006 & $\mathrm{P}_{131}$ & 5 \\
\hline $\mathrm{P}_{20}$ & 505 & $\mathrm{P}_{48}$ & 250 & $\mathrm{P}_{76}$ & 175 & $\mathrm{P}_{104}$ & 1013 & $\mathrm{P}_{132}$ & 50 \\
\hline $\mathrm{P}_{21}$ & 505 & $\mathrm{P}_{49}$ & 250 & $\mathrm{P}_{77}$ & 175 & $\mathrm{P}_{105}$ & 1020 & $\mathrm{P}_{133}$ & 5 \\
\hline $\mathrm{P}_{22}$ & 505 & $\mathrm{P}_{50}$ & 250 & $\mathrm{P}_{78}$ & 330 & $\mathrm{P}_{106}$ & 954 & $\mathrm{P}_{134}$ & 42 \\
\hline $\mathrm{P}_{23}$ & 505 & $\mathrm{P}_{51}$ & 165 & $\mathrm{P}_{79}$ & 531 & $\mathrm{P}_{107}$ & 952 & $\mathrm{P}_{135}$ & 42 \\
\hline $\mathrm{P}_{24}$ & 505 & $\mathrm{P}_{52}$ & 165 & $\mathrm{P}_{80}$ & 531 & $\mathrm{P}_{108}$ & 1006 & $\mathrm{P}_{136}$ & 41 \\
\hline $\mathrm{P}_{25}$ & 537 & $\mathrm{P}_{53}$ & 165 & $\mathrm{P}_{81}$ & 395.7215 & $\mathrm{P}_{109}$ & 1013 & $\mathrm{P}_{137}$ & 17 \\
\hline $\mathrm{P}_{26}$ & 537 & $\mathrm{P}_{54}$ & 165 & $\mathrm{P}_{82}$ & 56.9652 & $\mathrm{P}_{110}$ & 1021 & $\mathrm{P}_{138}$ & 7 \\
\hline $\mathrm{P}_{27}$ & 549 & $\mathrm{P}_{55}$ & 180 & $\mathrm{P}_{83}$ & 115.3572 & $\mathrm{P}_{111}$ & 1015 & $\mathrm{P}_{139}$ & 7 \\
\hline $\mathrm{P}_{28}$ & 549 & $\mathrm{P}_{56}$ & 180 & $\mathrm{P}_{84}$ & 115 & $\mathrm{P}_{112}$ & 94 & $\mathrm{P}_{140}$ & 27 \\
\hline $\begin{array}{l}\text { Minimum } \\
\text { cost }(\$ / h)\end{array}$ & 1559818.7289 & & & & & & & & \\
\hline
\end{tabular}

Table 8. Comparison and statistical analysis of various algorithms for test system 4

\begin{tabular}{|c|c|c|c|}
\hline Approach & $\begin{array}{c}\text { Min. cost } \\
\mathbf{( \$ / h )}\end{array}$ & $\begin{array}{c}\text { Mean cost } \\
\mathbf{( \$ / h )}\end{array}$ & $\begin{array}{c}\text { Standar } \\
\mathbf{d} \\
\text { deviation }\end{array}$ \\
\hline GSO[9] & $\begin{array}{c}1728151.168 \\
0\end{array}$ & $\begin{array}{c}1745514.997 \\
5\end{array}$ & - \\
\hline $\begin{array}{c}\text { CQGSO[9 } \\
\text { ] }\end{array}$ & 1657962.727 & 1657962.741 & - \\
\hline CSA [11] & 1655746.14 & 1655904.66 & 592.7 \\
\hline KHA [17] & 1560173.88 & $\begin{array}{c}1560176.744 \\
8\end{array}$ & - \\
\hline OKHA[17] & 1560146.95 & $\begin{array}{c}1560148.926 \\
4\end{array}$ & - \\
\hline SSO & $\begin{array}{c}1559818.728 \\
9\end{array}$ & $\begin{array}{c}1559839.583 \\
2\end{array}$ & 2.32 \\
\hline
\end{tabular}

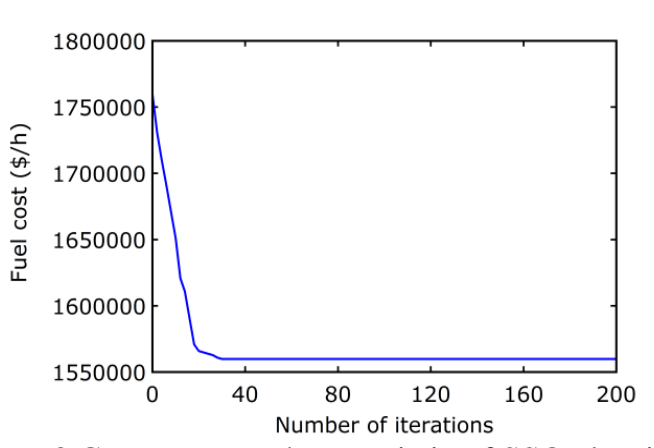

Figure. 3 Convergence characteristic of SSO algorithm for test system 4 


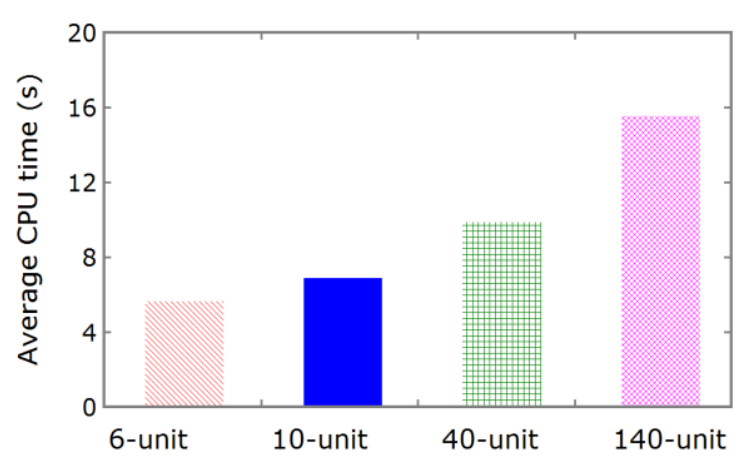

Figure. 4 Average CPU times of SSO algorithm for approach test systems

\section{Conclusion}

In this paper, a new meta-heuristic swarm approach based on squirrel search optimizer (SSO) algorithm is successfully employed to solve the different types of ELD problems. Many nonlinear generator characteristics such as POZs, ramp rate limits, VPL effects and MFOs are taken into

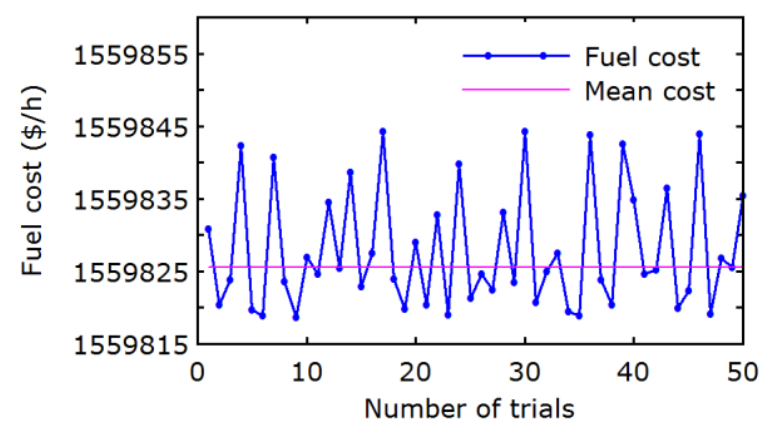

Figure. 5 Dissemination of fuel costs of the SSO approach for test system 4 in 50 different trials

consideration. In SSO, the predator presence behavior and a seasonal monitoring condition are incorporated to update the position of squirrel in a better way, which enhances the exploration and exploitation search abilities of the algorithm significantly. Moreover, the global search ability of the algorithm is further enhanced by Levy distribution. The efficacy of SSO algorithm is studied on four different test systems with various complexities, and the results are compared with other state-of-the-art heuristic approaches surfaced in the literature. The simulation results demonstrate that the SSO algorithm is superior to the other compared algorithms in terms of fuel costs, and standard deviation values. In addition, SSO has obvious advantages in terms of convergence rate. Then the robustness of the SSO algorithm is analyzed in fifty independent runs. In summary, these findings confirm that the suggested SSO approach is significantly better than the other algorithms. As a scope of further research, the SSO algorithm can be applied for solving complex unit commitment and dynamic ELD problems.

\section{Conflicts of Interest}

The authors declare no conflict of interest

\section{Author Contributions}

The contributions of authors are as follows: conceptualization: Vadugapalayam Ponnuvel Sakthivel; methodology, software, validation, formal analysis, investigation, and resources: Vadugapalayam Ponnuvel Sakthivel, Murugesan Suman, and Palanigounder Duraisamy Sathya; original draft preparation, review and editing, visualization, supervision, and project administration: Vadugapalayam Ponnuvel Sakthivel; and funding acquisition, Murugesan Suman.

\section{Nomenclature}

$\begin{array}{ll}a_{i}, b_{i}, c_{i} & \text { cost coefficients of the unit } i \\ a_{i j}, b_{i j}, c_{i j}, & \begin{array}{l}\text { cost coefficients of the unit } i \text { for } \\ \text { fuel type } j\end{array} \\ B_{i j}, B_{0 i}, \text { and } B_{00} & \begin{array}{l}\text { B-matrix coefficients for } \\ \text { transmission losses }\end{array} \\ C_{D} & \text { frictional drag coefficient } \\ C_{L} & \text { frictional lift coefficient } \\ d_{g} & \text { gliding distance } \\ D & \text { drag force } \\ e_{i} \text { and } f_{i} & \text { cost coefficients of the VPL effect } \\ e_{i j} \text { and } f_{i j} & \text { of unit } i \\ F_{i}\left(P_{i}\right) & \text { cost coefficients of the VPL effect } \\ G_{c} & \text { of unit } i \text { for fuel type } j \\ h_{g} & \text { total fuel cost of the generators } \\ k & \text { Gliding constant } \\ L & \text { gliding height } \\ n g & \text { index of prohibited zone } \\ n f & \text { lift force } \\ n z & \text { total number of generating units } \\ P_{d p} & \text { number of fuel types for each unit } \\ P_{D} & \text { total number of POZs } \\ P_{i} & \text { predator presence probability } \\ P_{i, m i n}, P P_{i, m a x} & \text { power demand } \\ P_{L} & \text { mower generation of } i \text { th unit } \\ r_{a} \text { and } r_{b} & \text { of unit } i \\ r_{1}, \text { and } r_{2} & \text { transmission losses } \\ S_{m i n} & \text { randomly distributed numbers in }[0,1] \\ S & \text { minimum valum }\end{array}$




\begin{tabular}{|c|c|}
\hline $\tan (\phi)$ & gliding angle \\
\hline$U R_{i}, D R_{i}$ & $\begin{array}{l}\text { up and down ramp limits of } i \text { th unit } \\
\text { respectively }\end{array}$ \\
\hline$V$ & speed \\
\hline$X_{a}$ & $\begin{array}{l}\text { position of squirrel individual which } \\
\text { reached the acorn tree }\end{array}$ \\
\hline$X_{h}$ & $\begin{array}{l}\text { position of squirrel individual which } \\
\text { reached the hickory tree }\end{array}$ \\
\hline$X_{L}, X_{U}$ & $\begin{array}{l}\text { lower and upper bounds of squirrel } \\
\text { individual }\end{array}$ \\
\hline & density of air \\
\hline & constant \\
\hline
\end{tabular}

\section{References}

[1] A. J. Rabih, H. C. Alun, and J. C. Brian, "A Homogeneous Linear Programming Algorithm for the Security Constrained Economic Dispatch Problem", IEEE Transactions on Power Systems, Vol. 15, No. 3, pp. 930-937, 2000.

[2] W. R. Barcelo and P. Rastgoufard, "Dynamic Economic Dispatch Using the Extended Security Constrained Economic Dispatch Algorithm", IEEE Transactions on Power Systems, Vol. 12, No. 2, pp. 961-967, 1997.

[3] A. A. El-Keib, H. Ma, and J. L. Hart, "Environmentally Constrained Economic Dispatch Using the Lagrangian Relaxation Method", IEEE Transaction on Power Systems, Vol. 9, No. 4, pp. 1723-1727, 1994.

[4] Z. L. Gaing, "Particle Swarm Optimization to Solving the Economic Dispatch Considering the Generator Constraints", IEEE Transactions on Power Systems, Vol. 18, No. 3, pp. 11871195, 2003.

[5] V. P. Sakthivel, "New Particle Swarm Optimizer with Nature Inspired Dynamic Inertia Weight for Economic Power Dispatch", Global Journal of Engineering Science and Researches, Vol. 5, No. 2, pp. 97-104, 2018.

[6] X. S. Yang, S. S. S. Hosseini, and A. H. Gandomi, "Firefly Algorithm for Solving NonConvex Economic Dispatch Problems with Valve Loading Effect", Applied Soft Computing, Vol. 12, No. 3, pp. 1180-1186, 2012.

[7] H. M. Dubey, M. Pandit, and B. K. Panigrahi, "A Biologically Inspired Modified Flower Pollination Algorithm for Solving Economic Dispatch Problems in Modern Power Systems", Cognitive Computation, Vol. 7, No. 5, pp. 594608, 2015.

[8] V. P. Sakthivel and P. D. Sathya, "Economic Load Dispatch Using Glowworm Swarm Optimization", International Innovative
Research Journal of Engineering and Technology, Vol. 3, No. 1, pp. 24-31, 2017.

[9] M. Moradi-Dalvand, B. Mohammadi-Ivatloo, A. Najafi, and A. Rabiee, "Continuous Quick Group Search Optimizer for Solving NonConvex Economic Dispatch Problems", Electric Power Systems Research, Vol. 93, pp. 93-105, 2012.

[10] M. Basu and A. Chowdhury, "Cuckoo Search Algorithm for Economic Dispatch", Energy, Vol. 60, pp. 99-108, 2013.

[11] D. N. Vo, P. Schegner, and W. Ongsakul, "Cuckoo Search Algorithm for Non-Convex Economic Dispatch", IET Generation, Transmission \& Distribution, Vol. 7, No. 6, pp. 645-654, 2013.

[12] A. Mandal, P. K. Roy, and S. Mandal, "Economic Load Dispatch Using Krill Herd Algorithm", International Journal of Electrical Power and Energy Systems, Vol. 57, pp. 1-10, 2014.

[13] N. Ghorbani and E. Babaei, "Exchange Market Algorithm for Economic Load Dispatch", International Journal of Electrical Power and Energy Systems, Vol. 75, pp. 19-27, 2016.

[14] M. Modiri-Delshad, S. H. Aghay Kaboli, E. Taslimi-Renani, and A. R. Nasrudin, "Backtracking Search Algorithm For Solving Economic Dispatch Problems with Valve-Point Effects and Multiple Fuel Options", Energy, Vol. 116, No. 1, pp. 637-649, 2016.

[15] M. Ghasemi, S. Ghavidel, J. Aghaei, E. Akbari, and L. I. Li, CFA optimizer.: "A New And Powerful Algorithm Inspired by Franklin's And Coulomb's Laws Theory for Solving the Economic Load Dispatch Problems", International Transaction on Electrical Energy Systems, Vol. 28, No. 5, e2536, 2018.

[16] M. Jain, V. Singh, and A. Rani, "A Novel Nature-Inspired Algorithm for Optimization: Squirrel Search Algorithm", Swarm and Evolutionary Computation, Vol. 44, No. 2, pp. 148-175, 2019.

[17] S. M. A. Bulbul, M. Pradhan, P. K. Roy, and T. Pal, "Opposition-Based Krill Herd Algorithm Applied to Economic Load Dispatch Problem", Ain Shams Engineering Journal, Vol. 9, No. 3, pp. 423-440, 2018. 